\section{EDUCAÇÃO PARA AS RELAÇÕES ÉTNICO- RACIAIS NA EDUCAÇÃO INFANTIL: A HISTÓRIA DE SOPHIA}

\author{
EDUCATION FOR ETHNIC-RACIAL RELATIONS IN EARLY CHILDHOOD \\ EDUCATION: THE STORY OF SOPHIA C्P
}

EDUCACIÓN PARA LAS RELACIONES ÉTNICO-RACIALES EN LA

EDUCACIÓN INFANTIL: LA HISTORIA DE SOPHIA C己

doi' https://doi.org/10.22456/1982-8918.108168

(iD) Alessandra Cristina Raimundo* <alecris04@yahoo.com.br>

Dinah Vasconcellos Terra** $<$ dv.terra@terra.com.br>

\footnotetext{
*Secretaria Municipal de Educação do Rio de Janeiro. Rio de Janeiro, RJ, Brasil.

**Universidade Federal Fluminense. Niterói, RJ, Brasil.
}

Resumo: O artigo é uma narrativa de pesquisa-formação na relação vivida entre professora e aluna produzido nas aulas de Educação Física na Educação Infantil. A história narrada mobiliza uma produção de saber/fazer que responde a um sentimento marcado pela existência do outro com objetivo de problematizar a história da cultura africana e as representações estéticas negras. O planejamento de ensino foi organizado por cenários da linguagem literária; oficina das bonecas Abayomi; jogos e brincadeiras da cultura africana e afro-brasileira. Foram percebidas algumas mudanças no comportamento das crianças negras, identificando-se um sentimento de pertencimento racial, visível na representatividade dos cabelos crespos e no fortalecimento da sua autoestima.

Palavras chave: Iniquidade étnica. Educação Física. Memória. Racismo.
Recebido em: 05 out. 2020 Aprovado em: 19 fev. 2021 Publicado em: 02 abr. 2021

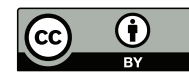

Este é um artigo publicado sob a licença Creative Commons Atribuição 4.0 Internacional (CC BY 4.0).

eISSN: $1982-8918$ 


\section{ONDE TUDO COMEÇA, ERA UMA VEZ...}

As experiências de preconceito racial vividas na escola, que envolvem o corpo, o cabelo e a estética, ficam guardadas na memória do sujeito. Mesmo depois de adultos, quando adquirem maturidade e consciência racial que thes permitem superar a introjeção do preconceito, as marcas do racismo continuam povoando a sua memória. (GOMES, 2003, p. 176).

Silêncio!! Na contemplação do silêncio permiti olhar, sentir, viver e narrar o indizível!! Eu vi vida nos olhos do outro, sem roteiro prefixado, percorri caminhos na busca de transgredir modelos normativos de pesquisa na tentativa de transpor o limite entre eu e o outro. A posição assumida como professora dessa narrativa não é a de um sujeito distante, sem se "expor", mas sim de um sujeito "ex-posto" com a abertura essencial para o "sujeito da experiência", como afirma Larrosa (2002, p.14), "seria algo como um "território de passagem, algo como uma superfície sensível que aquilo que acontece afeta de algum modo, produz alguns afetos, inscreve algumas marcas, deixa alguns vestígios, alguns efeitos".

A narrativa aborda uma experiência de pesquisaformação que, segundo Passeggi (2016), rompe com o paradigma aplicacionista em educação e reconhece nas experiências adquiridas no mundo do trabalho a possibilidade de "produzir teorias e conhecimentos sobre seus modos de fazer, de ser e de aprender" (p.75). Assim, o aprendizado vivido na relação entre professora e aluna, em um processo de reflexibilidade e de constantes interrogações, se desdobra em um movimento de descoberta de si não de forma isolada, mas no encontro, atravessada pela vida que se vê nos olhos do outro. Isso implica romper com a ideia de formação numa transposição pragmática, como um sujeito impassível aos acontecimentos, como algo que acontece fora de nós, incapaz de provocar questionamentos, para tanto, a experiência que nos toca atravessa o caminho, perpassa o tempo de aprendizagem e nos transforma. Como afirma Souza (2007, p.69):

[...] a constituição do trabalho docente levando-se em conta os diferentes aspectos de sua história: pessoal, profissional e organizacional, percebendo-se uma tomada de consciência que nos leva a reconhecer os saberes construídos pelos professores, no seu fazer pedagógico diário, o que não acontecia anteriormente nos modelos de formação de professores. Novos conceitos para a compreensão do trabalho docente surgiram com os estudos educacionais, cujas abordagens de pesquisa passaram a reconhecer o professor como sujeito, trazendo à tona a necessidade de se investigarem os saberes de referência dos professores sobre suas próprias ações e pensamentos caracterizando-os, inclusive, como sujeitos de um saber e de um fazer inerentes à profissão.

Esta experiência formativa aproxima do saber/fazer que responda a um sentimento marcado pela não indiferença da existência do outro e nos convida a dialogar com outro universo, legitimando e dando voz à palavra enquanto um sujeito de direito social, de sua capacidade de reflexão, independentemente de idade, gênero, diferenças étnico-raciais, profissão, posição social. Neste percurso formativo convido a conhecer e habitar o mundo de Sophia.

Epifania! No encontro do eu com o outro, emerge a epifania!! Assim me senti naquele outono de 2018, numa escola pública localizada na comunidade da 
Mangueira. Sophia ${ }^{1}$, aluna do Ensino Infantil de quatro anos de idade, ornada com coque alto nos cabelos, que parecia uma coroa, carregava em seu rosto um sorriso aberto e feliz, evidenciado na forma como participava da aula em que se apresentava solta, ávida, curiosa. Durante a aula de Educação Física, não percebi olhares ou atitudes estranhas dos seus colegas a respeito do seu penteado. Entretanto, no horário da saída, ao conduzir a turma ao portão, presenciei alunos de outra turma sorrindo debochadamente para Sophia. Eles disseram algo que não consegui ouvir. Ao olhar novamente para Sophia, que estava com uma blusa com capuz, percebi que escondia o penteado e seu rosto alegre carregava um semblante triste.

Assim, subitamente, ao me deparar com essa cena do cotidiano, fui afetada por uma multiplicidade de sentimentos. Não consigo responder há quanto tempo não me espantava com a realidade, sentindo-me perturbada, assim como Sophia. Logo, perguntei: o que estava acontecendo? Naquele instante, nos entreolhamos e o silêncio tomou conta daquele ambiente, os segundos pareciam horas. Assim, esquivando-se da pergunta, ela me responde: - Estão rindo do meu cabelo!

É lamentável presenciar cenas como esta em uma escola localizada na comunidade da Mangueira, constituída por uma grande população negra e identificada por uma agremiação da escola de samba a "Estação Primeira de Mangueira", produção cultural da população negra, e conviver, nos estereótipos, com crianças pequenas carregadas de linguagens impregnadas de preconceito racial. Essa cena não passou despercebida por Sophia. A tristeza expressa em seu rosto e o fato de esconder o cabelo nos revelam a dor e o sentimento de inadequação. Ela não estava se sentindo à vontade, estava envergonhada por ter cabelos crespos e cobri-los era uma forma de se tornar invisível e silenciar a sua existência.

Ao pensar sobre esse acontecimento, recuperei, em minhas memórias, cenas guardadas em segredo, "memórias subterrâneas" que se encontravam em meu inconsciente e subverteram o silêncio e, de maneira quase imperceptível, afloraram e revelaram verdades dolorosas (POLLAK, 1989). Os meus cabelos ondulados e a cor "parda" davam pistas da minha origem. Filha de uma mulher branca e um homem negro, vivi experiências de conflitos raciais que envolviam linguagens racistas, imagens dolorosas que pensei ter cicatrizadas. Lembro claramente do tom de humilhação vivido no ambiente escolar, ao ser chamada de "nega do cabelo duro", de estar inserida no próprio grupo social e, ao comprar o primeiro carro zero km, ouvir "Veja, só, a neguinha de carro novo!" ou ser confundida com a empregada da amiga branca. Hoje me pergunto: se fosse branca, seria confundida como empregada? O questionamento não se dá sobre a dignidade dessas profissões, mas como nos reduzem a determinados lugares e estereótipos a partir do pertencimento étnicoracial.

Por um longo período, fugi do assunto e sustentei uma visão colonizada sobre a questão, como sugere o sociólogo Gilberto Freyre, em Casa-Grande e Senzala 
(1933), vivemos em uma sociedade de harmonia entre as raças (GOMES, 2005). Contudo, a experiência vivida por Sophia e por tantas crianças no ambiente educativo formal ou informal revela uma situação que traz a representação de uma sociedade supremacista branca que internaliza o racismo profundamente em nossa consciência coletiva, como afirma Bell Hooks (2019).

Surpreendida com crianças na faixa etária da Educação Infantil com valores internalizados e reforçando padrões eurocêntricos, segui me interrogando: há quanto tempo estive imersa nesse cotidiano sem um olhar e uma escuta para práticas discriminatórias? Como agir como sujeito de resistência neste processo educacional? Como assistir a situações de caráter racista e não se sentir afetada? Será que, como professora de Educação Física, problematizo um saber/fazer voltado para processos de humanização da infância? Esses questionamentos constituem um movimento que exige uma reflexividade de nossa percepção de si, pessoal e profissional, sendo necessário reconhecer que as subjetividades fazem parte desse processo importante de transformação.

Assim, é preciso repensar e duvidar da perspectiva da história universal construída na invisibilidade e no apagamento de outras histórias. Dessa forma, entendendo a escola como uma instituição em que aprendemos e compartilhamos não só conteúdos e saberes escolares, mas como lugar de estabelecer relações sociais e culturais, por onde transitam conceitos, valores, crenças, espaço de debates e conflitos que dialogicamente favorecem a construção do conhecimento Nós, professoras e professores, reconhecemos, no ambiente educativo, práticas sociais que reforçam várias formas de exclusão e de assédio racistas.

Nilma Lino Gomes (2005, p.52) nos alerta sobre a complexidade do tema e nos exige uma racionalidade sensível ao lidar com a questão racial.

\begin{abstract}
O racismo é, por um lado, um comportamento, uma ação resultante da aversão, por vezes, do ódio, em relação a pessoas que possuem um pertencimento racial observável por meio de sinais, tais como: cor da pele, tipo de cabelo, etc. Ele é por outro lado um conjunto de ideias e imagens referente aos grupos humanos que acreditam na existência de raças superiores e inferiores. O racismo também resulta da vontade de se impor uma verdade ou uma crença particular como única e verdadeira.
\end{abstract}

É uma narrativa memorialística atravessada por uma atemporalidade, um acontecimento presente que interroga o passado rejeitando a minha própria negritude, negando a minha história, confrontando a posição de ser e estar no mundo. São experiências que, como afirma Bragança (2016, p. 11), "nos derrubam e transformam, inscritas na memória, são recriadas pela narrativa em um movimento reflexivo, potencialmente formador para aquele que narra e para os que ouvem".

Saí da escola pensando nesse episódio, visto que, até aquele momento, não havia presenciado essa situação entre crianças pequenas. Seria isso ou eu teria naturalizado o olhar frente a comportamentos racistas? Em que momento aceitei o silenciamento destas vozes e compactuei com este sistema opressivo?

Nesse sentido, trata-se de uma experiência formativa que me torna consciente da necessidade de reaprender o ensino sobre História e cultura africanas e afro-brasileiras, de reconhecer a luta dos movimentos sociais 
negros na busca de "igualdade de oportunidades para todos, possibilitando que os(as) historicamente excluídos(as) estejam presentes neste espaço-tempo de educação a que têm direito" (PIRES, 2006, p.107). Durante anos, reproduzimos em nossas escolas uma educação marcadamente eurocêntrica, reforçando modelos culturais e estéticos brancos, negando à população negra a condição de existência.

O episódio de Sophia me levou a prestar mais atenção nos espaços. Observei que, na exposição de painéis da escola, não havia representações estéticas negras, ou seja, essas vozes estavam sendo omitidas e silenciadas na própria comunidade escolar. De certa forma, isso não causa grande surpresa, visto que a sociedade brasileira nega o fato de precisarmos reparar as grandes desigualdades sociais sofridas pela população negra. Vivemos, ainda, "no mito da democracia racial, que defende que a sociedade brasileira não tem práticas racistas e que pessoas negras ou brancas têm as mesmas possibilidades de ascensão e sucesso sociais" (CAVALLEIRO, 2005, p.98).

Partindo dessa realidade, decidi organizar um planejamento de ensino sistematizando uma sequência de aulas para as turmas de Educação Infantil, selecionando conteúdos que levassem os(as) alunos(as) a conhecerem suas origens, afirmando sua identidade cultural. Reconheço que esses significados indicam a importância de

[...] conhecer e valorizar a pluralidade do patrimônio sociocultural brasileiro, bem como aspectos socioculturais de outros povos e nações, posicionando-se contra qualquer discriminação baseada em diferenças culturais, de classe social, de crença, de sexo, de etnia ou características individuais e sociais (BRASIL, 1997, p.7).

O planejamento teve como propósito explorar o tema da cultura africana e afro-brasileira para dialogar, de forma mais aprofundada, com as crianças. Senti a necessidade de lhes dar voz e protagonismo, buscando oportunizar, desde cedo, uma formação que seja capaz de

[...] conhecer diferentes realidades e compreender que a experiência social do mundo é muito maior do que a nossa experiência local, e que esse mesmo mundo é constituído e formado por civilizações, histórias, grupos sociais e etnias ou raças diversas. É também bem cedo em sua formação que as crianças podem ser reeducadas a lidar com os preconceitos aprendidos no ambiente familiar e nas relações sociais mais amplas. (BRASIL, 2014, p.15).

\section{EDUCAÇÃO FÍSICA E AS RELAÇÕES ÉTNICO-RACIAIS}

A Educação Física, enquanto componente curricular, sistematiza as práticas da cultura corporal, expressa nos jogos e brincadeiras, esportes, danças, lutas e ginástica. É necessário tratar pedagogicamente dos temas da cultura corporal, atribuindo-lhes sentidos e significados, já que esses temas refletem a sua construção sócio-histórica. Assim, é fundamental que a escola ofereça a possibilidade de discussão e reflexão crítica sobre os temas da cultura corporal, problematizando valores sociais de nossa sociedade, além de produzir conhecimentos para que os(as) alunos(as) possam, com autonomia, ser protagonistas na construção de uma sociedade justa. 
Os Parâmetros Curriculares Nacionais - PCNs - (BRASIL, 1997, p.25), especificamente na área de Educação Física, destacam:

\begin{abstract}
No âmbito da Educação Física, os conhecimentos construídos devem possibilitar a análise crítica dos valores sociais, tais como os padrões de beleza e saúde, que se tornaram dominantes na sociedade, seu papel como instrumento de exclusão e discriminação social e a atuação dos meios de comunicação em produzi-los, transmiti-los e impô-los; uma discussão sobre a ética do esporte profissional, sobre a discriminação sexual e racial que existe nele, entre outras coisas, pode favorecer a consideração da estética do ponto de vista do bem-estar, as posturas não-consumistas, não preconceituosas, não-discriminatórias e a consciência dos valores coerentes com a ética democrática.
\end{abstract}

A ideia da problematização do tema parte de um levantamento bibliográfico sobre produções científicas relacionadas à temática da Educação Física Escolar e às relações étnico-raciais. Entre as produções da área, destaco duas que abordam questões relacionadas às relações étnico-raciais na Educação Infantil. A pesquisa desenvolvida por Rangel (2006), intitulada "Educação Física na educação infantil: notas sobre a possibilidade de formação de preconceito étnico-racial", apresentou uma extensa revisão de literatura e observações assistemáticas da própria vivência da autora. Ela discute a construção do preconceito étnico-racial formado na Educação Infantil nas aulas de Educação Física, tendo como objetivo alertar professores(as) sobre a responsabilidade na formação de crianças e o cuidado permanente com as ações discriminatórias no ambiente educativo.

A pesquisa de Pereira, Gonçalves Júnior e Silva (2009), “Jogos africanos e afro-brasileiros no contexto das aulas de Educação Física”, faz um levantamento sobre jogos, brincadeiras, danças e contos de origem africana e afro-brasileira, para implementar tais atividades no projeto de recreação da prefeitura municipal de São Carlos/SP. Na investigação, observa-se sistematicamente e registra-se, por meio de um diário de campo, como ocorre o desenvolvimento das atividades e como estas contribuem nas reflexões, nos diálogos e na compreensão a respeito de diferentes culturas e identidades.

Tocada por essa experiência formativa, esse movimento de reflexividade me mobiliza na busca de um conhecimento que somente tem sentido pautado por um saber da sensibilidade. Como afirma Larrosa Bondía (2002, p.27), trata-se de "uma forma humana singular de estar no mundo, que é, por sua vez, uma ética (um modo de conduzir-se) e uma estética (um estilo)" na busca de práticas educativas democráticas para o pluralismo cultural e a diversidade étnico-racial na escola. Como diz Freire (1983), o professor não precisa abrir mão do conteúdo para problematizálo e dialogar com o mundo social. Isso porque é preciso muito mais do que saber o conteúdo a ser ensinado. Embora não seja uma tarefa simples, é necessária para não esvaziar a ação pedagógica de uma prática crítica e libertadora.

Assim, o planejamento de ensino intitulado: "Jogos e brincadeiras da cultura africana e afro-brasileira" buscou conhecer e vivenciar as origens e as representações simbólicas da cultura africana e afro-brasileira, a partir dos jogos e brincadeiras, com a finalidade de contribuir para o reconhecimento dessa cultura e construir uma identidade negra positiva. 
Acredito que o papel do professor é considerar o que acontece à sua volta, as demandas emergentes no cotidiano escolar e fomentar reflexões. Assim, o planejamento buscou, para além de conhecer a história da cultura africana e as representações estéticas negras que contribuem para a desconstrução de visões estereotipadas e preconceituosas sobre os corpos negros, pautar-se numa educação problematizadora e libertadora no sentido freiriano.

$\mathrm{Na}$ busca para organizar o planejamento, tive acesso a histórias infantis de meninas negras que tratam da representação estética do cabelo e cor da sua pele ${ }^{2}$. São histórias que ressaltam essas meninas como princesas, relatam o processo de fortalecimento e positivação da autoestima de nossas crianças, valorizando a beleza negra, mostrando que a estética branca não é a única existente, reafirmando a potência dessas histórias na construção de referenciais positivos para crianças negras. Ao fazer um levantamento sobre o tema dos cabelos crespos e cacheados de meninas e mulheres negras identifiquei na literatura infantil referências que contemplavam a temática, o que mostra que é possível ensinar e aprender por meio da leitura de contos, histórias e mitos africanos. A arte de contar histórias marca a tradição da cultura africana cujos contos

[...] são transmitidos de geração a geração pelos familiares, pela comunidade, pela escola, sobretudo por meio da oralidade, da arte de contar histórias que trazem diferenciadas visões de mundo, lições para a vida, lembranças para a memória coletiva. Nessas culturas valoriza-se aquele que consegue armazenar histórias e fatos em sua memória. Em muitas culturas, especialmente as tradicionais africanas, os guardiões da história em diversas regiões da África desenvolvem grande capacidade de memorizar o maior número de informações a respeito da linhagem de uma família, da organização política de um grupo, das funções de determinadas ervas utilizadas para a cura de doenças, da preservação das tradições: são os griots, contadores de história, guardiões da memória (SANTANA, 2006, p.44)

Iniciei o planejamento exibindo alguns vídeos (O mundo no Black Power de Tayó; O cabelo de Cora; A cor de Coraline). Comecei uma roda de conversa perguntando do que se tratava a história, se, em algum momento na escola, alguém tinha passado por alguma situação constrangedora por conta de cabelo e/ou cor da pele. Para minha surpresa, vários alunos disseram, sem medo, inclusive Sophia, que tinham vivenciado situações semelhantes à relatada.

Durante essa aula, enquanto passava um dos filmes para problematizar o tema, Sophia levantou-se devagar, dirigiu-se à frente da TV e me perguntou (diante de toda a turma, com um olhar e uma carinha de que havia descoberto algo)

- Professora! Quer dizer que eu sou negra? Respondi:

- Sim, você é negra.

De fato, era uma expressão de quem estava se descobrindo! Na sequência, vários(as) alunos(as) começaram a falar que também eram negros(as) e outros(as), ainda com dúvida, me perguntavam. Conversamos e anunciei que desenvolveríamos o tema da cultura africana e afro-brasileira com diferentes atividades. 
Na semana seguinte, na entrada das turmas, a mãe de Sophia me procurou e agradeceu. Ainda sem saber exatamente o motivo do agradecimento, perguntei por quê. Ela respondeu que a filha tinha chegado em casa dizendo que não queria ir mais à escola com aquele penteado. A mãe, uma pessoa esclarecida que assume sua identidade negra, estava com dificuldades com a filha sobre essa questão. O agradecimento fora porque, na aula seguinte, após a reprodução do filme e a realização do momento dos questionamentos, a filha chegara em casa e contara à mãe sobre o filme, o que havíamos conversado e o que faríamos em nossas aulas. A mãe relatou que Sophia já não a tensionava, ao fazer o penteado do seu cabelo, sentia que estava mais leve e com menos resistências, começando a reconhecer sua condição, ainda que várias perguntas e dúvidas continuassem.

A abertura para uma escuta acolhedora da mãe foi fundamental para persistirmos no caminho para o planejamento das próximas aulas. São essas experiências vividas no cotidiano escolar que nos mobilizam a resistir. Para Arroyo (2019, p. 9), "a resistência tende a crescer como um modo de produção de um novo sentido da existência social, um novo sentido da vida".

Esse trabalho na escola, hoje, conta com amparo legal. A Lei $n^{0} 10.639 / 03$ altera o artigo 26-A da Lei de Diretrizes e Bases da Educação Brasileira, incluindo a obrigatoriedade do ensino da História e cultura afro-brasileira e africana na Educação Básica, luta histórica de diversos(as) educadores(as) de escolas públicas brasileiras. A promulgação da lei não é apenas um processo burocrático-normativo.

Trata-se de um processo histórico e político de lutas e reivindicações expresso nos avanços da legislação. Esse avanço se realiza de forma gradual e complexa nas diferentes regiões do país, pois caminha lado a lado com a desigualdade social e regional, bem como com a luta pela efetiva democracia (BRASIL, 2014, p.12-13).

Iniciar a discussão sobre a diversidade cultural na Educação Infantil é possibilitar a essas crianças, no espaço escolar, o direito de serem respeitadas em suas diferenças, de conhecer e acolher as várias histórias de civilizações, grupos sociais e étnico-raciais diversos, ressaltando a importância e a riqueza de conhecer as contribuições da cultura africana na formação e constituição da nação brasileira.

De acordo com o Plano Nacional de Implementação da Lei n 10.639/2003,

O papel da educação infantil é significativo para o desenvolvimento humano, para a formação da personalidade e aprendizagem. Nos primeiros anos de vida, os espaços coletivos educacionais os quais a criança pequena frequenta são privilegiados para promover a eliminação de toda e qualquer forma de preconceito, discriminação e racismo. As crianças deverão ser estimuladas desde muito pequenas a se envolverem em atividades que conheçam, reconheçam, valorizem a importância dos diferentes grupos étnico-raciais na construção da história e da cultura brasileiras (BRASIL, 2003, p. 34).

\section{TRILHANDO O MUNDO DE SOPHIA...}

O planejamento teve início com o desenvolvimento da oficina de bonecas Abayomi $^{3}$. A ideia surgiu de um diálogo com uma professora de História contando

3 A palavra Abayomi, de origem iorubá, que costuma a ser uma boneca negra, significa aquele que traz felicidade 
a experiência vivida em sua escola com a proposição da confecção das Abayomi. Pensando nas oficinas, fiz o convite à professora que, ao mesmo tempo, nos ensinou o trabalho artesanal, sem deixar de lado a importância da história que envolve as Abayomi, pensando a boneca como elemento de resistência e fortalecimento da autoestima e da identidade afro-brasileira.

A proposição da oficina foi construída por uma ação conjunta com a participação das professoras regentes de sala e a professora da sala de leitura. O processo foi enriquecedor pois, coletivamente, compartilhamos ideias e reflexões sobre como implementar a lei $n^{\circ} 10.639 / 03$ em nosso currículo. As crianças estavam animadas. Por serem bem pequenas, necessitavam de auxílio para finalizar os nós necessários na confecção das bonecas.

Começamos dialogando com as crianças: "Vocês conhecem o continente africano?", "Sabem onde fica?". As respostas eram muitas em: "Não sei onde fica"; "É aqui perto, tia?". Usamos o mapa do continente africano durante a oficina a fim de que todos(a) tivessem conhecimento de sua localização, já que, na etapa de vivência dos jogos, voltaríamos várias vezes a esse continente. Logo após as respostas, apresentei a boneca de pano e contei sobre a história das bonecas Abayomi, herança cultural dos africanos. Para esse trabalho, além de ensinar o processo de criação, cabe destacar a prática social da oralidade desenvolvida de forma contextualizada e significativa com a finalidade de discutir a importância histórica, cultural e social em torno das bonecas.

Nas sociedades africanas, a oralidade é um elemento central na produção e manutenção das mais diversas culturas, dos valores, conhecimentos, ciência, história, modos de vida, formas de compreender a realidade, religiosidade, arte e ludicidade. A palavra falada, para os povos africanos, possui uma energia vital, capaz de criar e transformar o mundo e de preservar os ensinamentos. (BRASIL, 2014, p.33)

As crianças confeccionaram suas bonecas e puderam levá-las para casa. Destaco o envolvimento e a motivação em produzir o material. A história dessas bonecas causou curiosidade e várias perguntas foram feitas durante a oficina. Alguns perguntaram: "Podemos dar nomes às bonecas?", "Como aqueles retalhos poderiam criar uma boneca?". Surpreenderam-se quando perceberam a boneca vestida, com turbante. Logo tivemos um retorno dos pais sobre como as crianças reagiram, contando sobre a história e exibindo, orgulhosas, a boneca construída por elas.

Em diálogo com as professoras da Educação Infantil, combinamos que elas contassem a história do livro Os cabelos de Lelêt, que traz a história de uma menina que, insatisfeita com seus cabelos cacheados, deseja saber a origem de tantos cachinhos. Com a escolha do livro, procurávamos narrativas infantis que reconhecessem traços identitários da cultura negra na sociedade, percebendo as diferenças existentes na pluralidade étnica no país e valorizando-a. O livro apresenta um quadro de ilustrações com personagens negras com uma diversidade de

ou alegria. Abayomi quer dizer encontro precioso: abay=encontro e omi= precioso). O nome serve para meninos e meninas, indistintamente. Há outra versão da história do surgimento das bonecas Abayomi, Lena Martins, artesã maranhense, criou a cooperativa das bonecas Abayomi, na década de 1980, no contexto do Movimento Negro, organizando e buscando a sua identidade afrodescendente.

4 Autora do livro: Valéria Belém e ilustrações de Adriana Mendonça. 
penteados nos cabelos. Sentados em roda para ouvir, problematizamos algumas questões: Como era o cabelo de Lelê? Como Lelê se sentia, ao conhecer sua história? Quais as diferenças e semelhanças com minha história? Identifico-me com essa história? As crianças pediam para mostrar as ilustrações dos livros repetidas vezes, uma vez que se sentiam representadas.

No compartilhamento de ideias, a professora regente sugeriu elaborarmos um jogo de memória, como material pedagógico, para que as crianças valorizassem a representatividade e a beleza estética dos cabelos crespos.

Essa angústia da personagem faz parte do cotidiano dos(as) alunos(as) de nossas escolas. Como fomos colonizados por um modelo de sociedade branca, europeia, patriarcal, não perspectivando outras referências, percebemos o quanto é difícil descontruir estereótipos. Nesse processo, a literatura pode desempenhar um papel importante.

Diante da necessidade de descolonizar o ensino nas escolas é preciso considerar a literatura como uma das possibilidades de ressignificação de saberes e conhecimentos, e para isso o professor deve saber analisar e escolher os textos a serem utilizados, recuperando histórias que foram silenciadas pela colonialidade do poder, representando a voz subalternizada pela história oficial, e fortalecendo identidade étnico racial do aluno afrodescendente (RODRIGUES; ROSA, 2018, p. 4).

$\mathrm{Na}$ escola, observamos as mudanças ocorridas com as crianças da Educação Infantil, principalmente em relação à questão estética. Várias alunas começaram a aparecer na escola com penteados de tranças embutidas com miçangas dos vários tipos, cores e tamanhos, laços, coque, moicano com tranças. A criatividade na elaboração dos penteados ficava a critério das mães que desenhavam diferentes e novos estilos.

Aaproximação com as famílias me proporcionou, na entrada e saída da escola, conversas cotidianas sobre seus filhos e esclarecimentos sobre os questionamentos a respeito do que estava acontecendo nas aulas e sobre a lei $n^{\circ} 10.639 / 03$, que apontava uma nova orientação para uma educação antirracista. Alguns não sabiam da existência da lei e outros responsáveis comentavam não ver essas questões, de fato, serem debatidas no âmbito escolar. Fiquei surpresa porque esse diálogo com os pais e a família foi movido a partir das crianças que levaram o tema para casa.

Com a sequência das aulas, partimos para os jogos da cultura africana e afrobrasileira, como o jogo do Labirinto (Moçambique), que possui uma dinâmica simples e interessante. Identificamos o país no sul do continente africano. Para começar, é preciso que se faça um desenho do labirinto no chão, seguindo os passos: (a) os jogadores iniciam o jogo na extremidade do desenho; (b) para seguir em frente, propomos o desafio da pedra, papel e tesoura. Toda vez que um jogador ganha, ele segue para a extremidade à frente; (c) o jogador que chegar à última extremidade primeiro vence a partida.

A proposta do jogo da amarelinha africana, diferentemente do modo de jogar que conhecemos, não usa uma pedrinha. O formato é diferente, não há uma brincadeira de competição, não há perdedores e utiliza-se uma música. São quatro 
participantes ao mesmo tempo com o propósito de executar a coreografia de forma sincronizada.

A proposta do jogo da capoeira, importante manifestação da cultura brasileira reconhecida pela Unesco como Patrimônio Cultural Imaterial da Humanidade, nos trouxe a história da "força da resistência contra a escravidão e a síntese da expressão de diversas identidades étnicas de origem africana" (OLIVEIRA, 2009, p. 43). Antes de iniciarmos, buscamos recolher dados com os alunos a respeito do conhecimento sobre a capoeira. Identificamos, entre os(as) alunos(as), capoeiristas participantes do grupo de capoeira da comunidade. Utilizamos o livro da capoeira da escritora Sônia Rosa para introduzir o tema. É um pequeno livro com destaque para as imagens ilustrativas dos personagens negros e negras e a possibilidade de homens, mulheres, crianças, idosas independentemente de idade, gênero, praticarem a capoeira. Não se trata de uma luta solitária, mas é com o outro que também temos a oportunidade de aprender.

Convidamos o mestre de capoeira Polako, de 76 anos, para nos contar sobre a história da capoeira e sua inserção no movimento da capoeira no Rio de Janeiro. Além disso, exímio capoeirista transmitiu-nos seu saber/fazer acumulado na tradição da capoeira. Conhecemos os toques dos instrumentos, o canto, os golpes e realizamos a roda de capoeira.

Acompanhando o processo de desenvolvimento dos jogos, tanto o labirinto Moçambique, a amarelinha africana quanto a capoeira despertaram o desejo dos alunos em experienciar intensamente os movimentos, golpes e jogadas. Foi possível verificar, nos momentos da entrada da escola, nos corredores, como essas atividades foram reinventadas nos espaços da escola. Identifico que essa movimentação e entusiasmo provocaram uma vontade das crianças em aprender de forma lúdica, o que se manifestava pelos sorrisos estampados no rosto, ao vivenciarem essas práticas corporais aprendidas.

Finalizando o planejamento havia previsto uma feira cultural da Educação Física com o tema "Jogos e brincadeiras da cultura africana e afro-brasileira" para exposição e apresentação das turmas que vivenciaram o planejamento. Ao dialogar com a coordenadora pedagógica, sugeriu divulgar os trabalhos desenvolvidos na I feira cultural da Escola, aberta à comunidade escolar cujo tema era "90 anos do Grêmio Recreativo da Escola de Samba Estação Primeira da Mangueira" como culminância de encerramento das atividades do ano letivo.

Contamos com o protagonismo dos(as) alunos(as) na apresentação dos materiais produzidos e compartilhamos saberes e conhecimentos sobre a história da África com a comunidade escolar. Organizamos uma tenda na quadra da escola com a exposição dos materiais didáticos - painéis com fotos dos alunos na oficina das bonecas Abayomi, na oficina de capoeira, os jogos e brincadeiras desenvolvidos nos momentos das aulas. Realizamos uma mostra das bonecas confeccionadas, organizamos as brincadeiras da amarelinha africana e o labirinto Moçambique onde as crianças partilhavam o saber aprendido nas aulas com os pais e/ou responsáveis. 
Compreendendo esse momento como importante para dar visibilidade ao papel da cultura negra na constituição da sociedade brasileira, trouxemos outro olhar acerca da representatividade do negro para a construção de uma identidade positiva para as crianças.

\section{E A HISTÓRIA CONTINUA...}

É inegável o fato da existência do racismo na sociedade brasileira, nas relações interpessoais do cotidiano escolar. Assim sendo, é necessário incluir, no projeto político pedagógico, ações pedagógicas envolvendo professores, alunos e comunidade escolar sobre o tema das relações étnico-raciais. Como diz Freire (2013), a escola é uma possibilidade concreta e responsável em organizar ações de resistência a questões repressoras internas e externas. Nesse sentido, a escola, como espaço do diálogo com a pluralidade cultural, deve questionar os contextos sociais e revelar dialeticamente as lutas históricas e o processo de libertação para uma educação antirracista.

Para que a escola consiga avançar neste debate, é preciso olhar para crianças negras silenciadas no cotidiano escolar. Aos professores cabe dar-lhes voz, pensar sobre a necessidade de construir intervenções críticas que desafiem e se oponham a um sistema de pensamento etnocêntrico, buscando, no reconhecimento da história da cultura africana e afro-brasileira, estratégias pedagógicas que podem contribuir para o processo de construção da autoestima de alunos(as).

Nesse sentido, temas oriundos do cotidiano escolar devem ser problematizados, o que nos faz compreender o sentido deliberativo do planejamento de ensino, sua função social e política no ato educativo. Desenvolver o planejamento sobre o tema das questões étnico-raciais e relacioná-los, sem abrir mão da especificidade da Educação Física, me encorajou a constantes reflexões durante o processo, considerando, ainda, a localização da escola em uma comunidade majoritariamente negra e a negação de reconhecer a identidade cultural. Isso nos revela que uma educação libertadora se faz com uma postura crítica e uma prática docente atenta aos acontecimentos de práticas discriminatórias.

É importante lembrar que as ações desenvolvidas nas aulas de Educação Física nos permitem refletir sobre questões sociais pertinentes aos debates da sociedade e dialogam com valores democráticos e princípios inclusivos. Nós, professores(as), devemos mobilizar o olhar para perceber a dor, a hostilidade sentidas por crianças que convivem cotidianamente com práticas discriminatórias sociais relativas às diferenças étnico-raciais, de gênero, de habilidades motoras, de composição corporal, de classe e de deficiências físicas.

Considerando a Educação Infantil como terreno fértil para a possibilidade de valorização das várias linguagens visuais, sons, falas, escritas, percebemos a necessidade de criar um espaço para explorar a literatura infantil. A contação de histórias nos revelou aprendizagens que puderam ser expressadas nas perguntas, dúvidas, em suas subjetividades, o que leva a compreender que, desde pequenas, as crianças devem construir sua identidade por meio de intervenções pedagógicas reflexivas, questionadoras, a fim de construir seus conhecimentos. 
As histórias possibilitaram às crianças outras formas de interpretar o mundo. Elas se identificaram com suas personagens e alimentaram um sentimento de pertencimento racial, visível na representatividade dos cabelos crespos e na beleza da menina negra. Os jogos da cultura africana foram recebidos, com entusiasmo, pelas crianças que adotaram uma linguagem corporal de respeito com o outro, fundamental para lidar com as diferenças de cor, habilidades, gênero.

A experiência formativa provocada pela história de Sophia tornou-se um caminho de transformação pessoal e profissional, um movimento de reflexão de quem narra suas experiências formativas em um processo de libertação, de conhecimento, sobretudo no comprometimento em assumir nesse processo uma postura política na garantia da igualdade de direitos e para uma educação antirracista. Obrigada, Sophia, você me inspira, sua história agora é nossa, pois ela me virou do avesso, dando sentido à minha ação educativa!

\section{REFERÊNCIAS}

ARROYO, Miguel. Vidas ameaçadas: Exigências-respostas Éticas da Educação e da docência. Petrópolis: Vozes, 2019.

BELÉM, Valéria. O cabelo de Lelê. São Paulo: Companhia Editora Nacional, 2007.

BRAGANÇA, Inês Ferreira de Souza. Sobre a escrita de memoriais: Caminhos de transformação. In: SILVA, Aline Gomes da et al. (orgs.) Memoriais de formação: narrativa e autoria no processo formativo docente. São Gonçalo (RJ): UERJ/FFP, 2016. p. 10-17.

BRASIL. Lei 10.639, de 9 de janeiro de 2003. Diário Oficial da União, 10 jan. 2003. Disponível em: http://www.planalto.gov.br/ccivil_03/leis/2003/110.639.htm. Acesso em: 6 mar. 2021.

BRASIL. Ministério da Educação. Plano Nacional das Diretrizes Curriculares Nacionais para a Educação das Relações Étnico-Raciais e para o Ensino de História e Cultura Afro-Brasileira e Africana. Brasília, DF: MEC/SECAD; SEPPIR, jun. 2009.

BRASIL. Ministério da Educação. Universidade Federal de São Carlos. História e cultura africana e afro-brasileira na educação infantil. Brasília: MEC/SECADI, UFSCar, 2014.

BRASIL. Ministério da Educação e do Desporto. Secretaria de Educação Fundamental. Parâmetros Curriculares Nacionais: Educação Física. Brasília: MEC/SEF, 1997.

CAVALLEIRO, Eliane dos Santos. Discriminação racial e pluralismo em escolas públicas da cidade de São Paulo. In: SECAD - Secretaria de Educação continuada, Alfabetização e Diversidade. Educação anti-racista: caminhos abertos pela Lei Federal n 10.639/03. Brasília: MEC/SECAD, 2005. p.65-104. (Coleção Educação para todos).

FREIRE. Paulo. Educação como prática da liberdade. Rio de Janeiro: Paz e Terra, 1983.

FREIRE. Paulo. Pedagogia da autonomia: saberes necessários a prática educativa. Rio de Janeiro: Paz e Terra, 2013.

GOMES, Nilma Lino. Alguns termos e conceitos presentes no debate sobre relações raciais no Brasil: uma breve discussão. In: SECAD - Secretaria de Educação continuada, Alfabetização e Diversidade. Educação anti-racista: caminhos abertos pela Lei Federal $n^{\circ}$ 10.639/03. Brasília: MEC/SECAD, 2005. p.133-166. (Coleção Educação para todos). 
GOMES, Nilma Lino. Betina. Belo Horizonte: Mazza, 2009.

GOMES, Nilma Lino. Educação, identidade negra e formação de professores/as: um olhar sobre o corpo negro e o cabelo crespo. Educação e pesquisa, v. 29, n. 1, p. 167-182, 2003.

HOOKS, bell. Olhares negros: raça e representação. São Paulo: Elefante, 2019.

LARROSA BONDÍA, Jorge. Notas sobre a experiência e o saber da experiência. Revista Brasileira de Educação, n. 19, p. 20-28, jan./abr. 2002.

OLIVEIRA, Josivaldo Pires de. Capoeira, identidade e gênero: ensaios sobre a história social da capoeira no Brasil. Salvador: EDUFBA, 2009.

PASSEGI, Maria da Conceição. Narrativas da experiência na pesquisa-formação: do sujeito epistêmico ao sujeito biográfico. Roteiro, v. 41, n. 1, p. 67-86, jan./abr. 2016.

PEREIRA, Alesandro A.; GONÇALVES JUNIOR, Luiz; SILVA, Petronilha B. G. e. Jogos africanos e afro-brasileiros no contexto das aulas de educação física. In: CONGRESSO DA ASSOCIATION INTERNATIONALE POUR LA RECHERCHE INTERCULTURELLE (ARIC): diálogos interculturais: descolonizar o saber e o poder. 12., 2009, Florianópolis. Anais... Florianópolis: UFSC, 2009. p.1-18.

PIRES, Rosane de Almeida. Educação de jovens e adultos. In: BRASIL.Ministério da Educação/Secretaria da Educação Continuada, Alfabetização e Diversidade. Orientações e Ações para Educação das Relações Étnico-Raciais. Brasília: MEC/SECAD, 2006.

POLLAK, Michael. Memória, Esquecimento, Silêncio. Revista Estudos Históricos, v. 2, n. 3, p. 3-15, 1989.

RANGEL, Irene C. A. Educação Física na educação infantil: notas sobre possibilidade de formação de preconceito étnico-racial. Identificando estilos de ensino em aulas de educação física em segmentos não escolares. Revista Mackenzie de Educação Física e Esporte, v. 5, n. 1, p. 135-146, 2006.

RODRIGUES, Elaine Borges; ROSA, Ana Lara Dalla. Literatura infantil e a descolonialidade: uma análise da obra "o cabelo de lelê. In: CONGRESSO DE PESQUISA EM EDUCAÇÃO: CONPEDUC 2018, Rondonópolis. Anais... Universidade Federal de Mato Grosso Campus Universitário de Rondonópolis 2018. Disponível em: https://www.even3.com.br/ anais/conpeduc2018/. Acesso em: 6 mar. 2021.

SANTANA, Patrícia Maria de Souza. Educação Infantil. In: BRASIL. Ministério da Educação/ Secretaria da Educação Continuada, Alfabetização e Diversidade. Orientações e Ações para Educação das Relações Étnico-Raciais. Brasília: MEC/SECAD, 2006. p. 31 - 51.

SOUZA, Elizeu Clementino de. (Auto)biografia, histórias de vida e práticas de formação. In: NASCIMENTO, Antônio Dias; HETKOWSKI, Tânia Maria (Orgs.). Memória e formação de professores. Salvador: EDUFBA. 2007. p.58-74. 
Abstract: This article is a narrative about a formative-research experience on the interaction between teacher and student produced in Physical Education classes in early childhood education. The story narrated mobilizes production of know-how that responds to a feeling marked by the other's existence to discuss the history of African culture and black aesthetic representations. The Lesson Plan was organized according to literary language scenarios; Abayomi doll workshop; symbolic games in African and Afro-Brazilian culture. Some changes were observed in the behavior of black children, and a sense of racial belonging was identified, which was visible in the representativeness of curly hair and strengthening of their self-esteem.

Keywords: Ethnic inequality. Physical Education. Memory. Racism.

Resumen: El artículo es una narración de investigación/formación en la relación entre profesora y alumna producida en las clases de Educación Física en la Educación Infantil. La historia narrada moviliza una producción de conocimiento/acción que responde a un sentimiento marcado por la existencia del otro para problematizar la historia de la cultura africana y las representaciones estéticas negras. El plan de enseñanza fue organizado por escenarios del lenguaje literario, taller de muñecas Abayomi y juegos de la cultura africana y afrobrasileña. Se observaron algunos cambios en el comportamiento de los niños negros, identificando un sentimiento de pertenencia racial, visible en la representatividad del cabello crespo y en el fortalecimiento de su autoestima.

Palabras clave: Inequidad étnica. Educación Física. Memoria. Racismo. 


\section{LICENÇA DE USO}

Este é um artigo publicado em acesso aberto (Open Access) sob a licença Creative Commons Atribuição 4.0 Internacional (CC BY 4.0), que permite uso, distribuição e reprodução em qualquer meio, desde que o trabalho original seja corretamente citado. Mais informações em: http://creativecommons.org/licenses/by/4.0

\section{CONFLITO DE INTERESSES}

Os autores declararam que não existe nenhum conflito de interesses neste trabalho.

\section{CONTRIBUIÇÕES AUTORAIS}

Alessandra Cristina Raimundo: Fundamentação; metodologia; descrição e análise da pesquisa.

Dinah Vasconcellos Terra: Fundamentação; metodologia; descrição e análise da pesquisa

\section{FINANCIAMENTO}

O presente trabalho foi realizado com apoio da Coordenação de Aperfeiçoamento de Pessoal de Nível Superior - Brasil (CAPES) - Código de Financiamento 001. This study was financed in part by the Coordenação de Aperfeiçoamento de Pessoal de Nível Superior - Brasil (CAPES) - Finance Code 001.

\section{ÉTICA DE PESQUISA}

O projeto de pesquisa seguiu as Diretrizes ético-política da produção científica do Regimento do PPGed/UFF.

\section{COMO REFERENCIAR}

RAIMUNDO, Alessandra Cristina; TERRA, Dinah Vasconcellos. Resistência na educação infantil: a história de Sophia. Movimento (Porto Alegre), v.27, p. e27018, jan./dez. 2021. Disponível em: https://seer.ufrgs.br/Movimento/article/ view/108168. Acesso em: [dia] [mês abreviado]. [ano]. DOI: https://doi.org/ $\underline{10.22456 / 1982-8918.108168}$

\section{RESPONSABILIDADE EDITORIAL}

Alex Branco Fraga*, Elisandro Schultz Wittizorecki*, Ivone Job*, Lisandra Oliveira e Silva*, Mauro Myskiw*, Raquel da Silveira*

*Universidade Federal do Rio Grande do Sul, Escola de Educação Física, Fisioterapia e Dança, Porto Alegre, RS, Brasil. 